\title{
Sociologie
}

Sociologie 15(3): 383 - 393

(C) De auteur(s) 2019 (c) CC BY NC ND 4.0 () (c) (1)

https://doi.org/10.5117/soc2019.3.011.haan

\section{Boekbespreking \\ Het Duitse ordoliberalisme-debat: Thomas Biebricher over ordoliberale ideeën en praktijken in Duitsland, Europa en de wereld}

Ido de Haan

Universiteit Utrecht

i.dehaan@uu.nl
De favoriete beeldspraak van Thomas Biebricher, een van de meest productieve auteurs over het neoliberalisme, is ontleend aan de film The Usual Suspects, waarin de ongrijpbare schurk Keyser Söze zich tot het publiek richt met de uitspraak: 'The greatest trick the devil ever pulled was convincing the world that he doesn't exist'. Dit zou volgens Biebricher een treffende karakterisering zijn van het neoliberalisme, dat zich lastig laat definiëren en waarvan de invloed moeilijk is vast te stellen. Niettemin meent Biebricher dat er een reeks van neoliberale ideeën geïdentificeerd kan worden en dat een specifieke Duitse variant van het neoliberalisme - het ordoliberalisme - de laatste decennia van doorslaggevende invloed is geweest op de Europese politiek. Daarmee biedt zijn werk zicht op de ordoliberale variant van het neoliberalisme, die in Nederland, maar eigenlijk overal buiten Duitsland, weinig besproken is.

Hoe die invloed van dit Duitse neoliberalisme precies begrepen moet worden, blijkt evenwel lastig, zo blijkt uit het werk van Biebricher. Centraal in zijn perspectief op het neoliberalisme staat de gedachte 
dat dit geen economische theorie over de markt is, maar een politieke theorie, georganiseerd rond een reeks van denkbeelden over de staat, democratie, de rol van de wetenschap, en uiteindelijk over de aard van politiek zelf. Dat gezichtspunt levert een reeks relevante theoretische vergezichten op, maar niettemin dreigt het neoliberalisme als maatschappelijk verschijnsel in Biebrichers werk achter de horizon te verdwijnen.

Thomas Biebricher was van 2014 tot 2017 hoogleraar politieke theorie en filosofie aan de Goethe Universiteit in Frankfurt am Main, en geeft op dit moment leiding aan het 'Exzellenzcluster' aan dezelfde universiteit rond het thema van 'die Herausbildung normativer Ordnungen'. Hij begon na een studie in de politieke wetenschap aan de Albert Ludwigs Universiteit in Freiburg en de Queen's University in Kingston (Canada) zijn carrière met een dissertatie over Selbstkritik der Moderne. Habermas und Foucault im Vergleich (Biebricher 2005). Die worteling in de kritische theorie en het poststructuralisme tekent ook zijn benadering van het neoliberalisme: hij ziet dat in poststructuralistische zin als een conglomeraat van ideeën, van uiteenlopende herkomst en met onderling inconsistente implicaties, maar ook als een reeks beleidspraktijken, die niet alleen in verschillende nationale contexten op uiteenlopende wijze vorm krijgen, maar bovendien op complexe wijze verbonden zijn met neoliberale theorievorming. In The Political Theory of Neoliberalism identificeert hij zijn doel als 'neither a refutation nor an unmasking in the sense of ideology critique but rather a problematization of neoliberalism's political theory' (Biebricher 2018: 10). Desondanks loopt zijn werk, in de traditie van de kritische theorie, uit op een verwerping van de ordoliberale invloed op de Europese politiek: 'The competitive order of Europe instead needs to be repoliticized, and, more specifically, it needs to be democratized. In other words, it needs to be less ordoliberal' (Biebricher 2018a: 224).

\section{Het neoliberale gedachtengoed}

Biebrichers uiteenzetting van neoliberale ideeën heeft sinds zijn discussie daarvan in Neoliberalismus zur Einführung (Biebricher 2012) aan scherpte gewonnen. In die Duitstalige studie beschrijft hij het neoliberalisme in de eerste plaats als de vrucht van de scheiding tussen politiek en economie die al rond 1890 met het werk van Alfred Marshall vorm kreeg in de verschuiving van staathuishoudkunde en politieke economie naar 'economics' als zelfstandige discipline. Het neoliberalisme onderscheidde zich vervolgens van Marshalls neoklassieke visie op de vrije markt als spontane orde. De pogingen van denkers als Ludwig von Mises en Friedrich August Hayek in Wenen, Walter Eucken en Wilhelm Röpke in Freiburg, Edwin Cannan en Lionel Robbins in London, en Frank H. Knight in Chicago moeten juist gezien worden als poging het liberalisme te ontdoen van het laisser-faire-denken. Volgens de neoliberalen was er juist actief overheidsingrijpen nodig om de vrije markt te beschermen tegen monopolievorming en belangengroepen die allerlei 
marktverstorende maatregelen eisten. De Duitse tak van deze neoliberale stroming was gegroepeerd rond het blad Ordo en werd derhalve ordoliberalisme genoemd.

De neoliberale theorievorming kwam op gang onder invloed van de sociale kwestie en de industriële schaalvergroting aan het eind van de negentiende eeuw; in reactie op de groeiende rol van staat tijdens de Eerste Wereldoorlog, in de SovjetUnie en in Weimar- en Nazi-Duitsland; en in antwoord op de economische crisis van de jaren twintig en de ondergang van de parlementaire democratie in de jaren dertig. Het streven om het liberalisme te herdefiniëren vond vanaf het Walter Lippmann-colloquium in 1938 in Parijs plaats onder het zelfgekozen label van het 'neoliberalisme'. Net als John Maynard Keynes, die in 1924 'The end of laisser faire' aankondigde, bekommerden vroege neoliberalen zich om de levensvatbaarheid van de markteconomie. Anders dan Keynes, die meende dat de markt gered kon worden door de werking ervan in te perken, meenden neoliberalen dat de markt constitutioneel afgeschermd en sociaal-cultureel ingebed diende te worden waarbij het verschil tussen keynesiaans ‘inperken' en neoliberaal 'afschermen' dus wellicht eerder gradueel dan principieel van aard was.

Naast deze economische kritiek, was de kritiek op de democratie een andere belangrijke pijler onder het vroege neoliberalisme. Biebricher ontwaart een ordoliberale parlementarismekritiek langs lijnen die ook werden verkend door Carl Schmitt, waarin het pluralisme van deelbelangen de staat instrumentaliseert en verzwakt. Dit kan alleen opgelost worden door de 'Isolierung staatliche Willensbildung von entsprechende gesellschaftlichen Willensbildungprozessen' (Biebricher 2012: 47). Hieruit spreekt een breed gedeeld wantrouwen ten aanzien van de massademocratie, en van het vermogen van gewone burgers om de werking van de economie te doorgronden. Het vroege neoliberalisme liep derhalve uit op een pleidooi voor 'autoritär-expertokratische Überwindung der pluralistischen Massendemokratie' (Biebricher 2012: 48-49).

In Neoliberalismus zur Einführung bespreekt Biebricher vervolgens het werk van de Freiburgse ordoliberalen Walter Eucken, Wilhelm Röpke en Alexander Rüstow (die nooit in Freiburg had gewerkt maar het gedachtegoed van de andere twee deelde); de grondlegger van de public choice-theorie James Buchanan; het 'evolutorischer Neoliberalismus' van Friedrich Hayek; en het monetaristische neoliberalisme van Milton Friedman. De veelheid aan namen en benamingen maakt duidelijk dat het neoliberalisme een grote variatie aan antwoorden geeft op crisis van het liberalisme. Het Duitse neoliberalisme, met zijn nadruk op de sterke staat, stond op gespannen voet met de meer libertaire, anti-etatistische stroming binnen het neoliberalisme (zoals dat wel te vinden is bij Ludwig von Mises tot en met Robert Nozick, en in mindere extreme mate bij Hayek en Friedman). Tegelijk stonden de verschillende neoliberalen in een complexe relatie tot het conservatisme. Zo werd het cultuurpessimisme en de voorliefde voor kleinschalig communitarisme overgenomen, alsook de epistemologische kritiek en het evolutionaire denken. Maar neoliberalen hadden weinig op met de conservatieve afkeer van innovatie en de voorliefde voor een disciplinerende nationale staat. 


\section{De politieke theorie van het neoliberalisme}

Deze ideeënhistorische analyse zet Biebricher voort in The Political Theory of Neoliberalism (2018a), maar daar kiest hij nadrukkelijker voor een politiektheoretische invalshoek. Zoals ook duidelijk wordt uit de Nederlandse vertaling van enkele recente artikelen van Biebricher (2017), vormt niet de markt maar de politieke theorie de kern van de 'neoliberal problematic' (Biebricher 2018a: 27). Hij analyseert die politieke theorie niet langer per auteur, maar thematisch, waardoor hij nu beter in staat is de onderlinge verhoudingen tussen neoliberale stromingen en de historische ontwikkeling van het neoliberale ideeëngoed te analyseren.

Vanuit politiek-theoretisch gezichtspunt gezien is het neoliberalisme om te beginnen een theorie van de staat. Daarbij schetst Biebricher de neoliberale staat in oplopende gradatie van interventie. In de eerste plaats is de staat een scheidsrechter.Zoals Milton Friedman stelde, heeft de staat als taak 'to do something that the market cannot do for itself, namely, to determine, arbitrate and enforce the rules of the game' (Biebricher 2018a: 35; vgl. Friedman 2002: 27). Een stap verder is dat de staat niet alleen de regels van de markt bewaakt, maar zelfdestructieve tendensen van de markt, in het bijzonder de vorming van monopolies, tracht tegen te gaan. Nog verder reikend staatsingrijpen is volgens neoliberalen als Rüstow nodig om de erosie van sociale verbanden als gevolg van het individualisme van de markt tegen te gaan. Hij pleit voor een conservatieve Vitalpolitik die de vervreemding van het individu in een massamaatschappij tegen moet gaan.

Kern van de neoliberale problematiek is derhalve niet de rol van de staat zo ver mogelijk terug te dringen, maar te identificeren waar staatsingrijpen de markt nog bevordert, en op welk punt dit het marktmechanisme gaat verstoren. Hoewel allerlei pogingen worden ondernomen het verschil aan te wijzen tussen wat Buchanan aanduidt als het bewaken van de constitutie door de 'protective state', en de prijsverstorende werking van de 'productive state', blijft dit een heikel punt in de neoliberale theorievorming.

Opvallend is vervolgens dat neoliberalen geen fiducie hebben in een democratische oplossing van dit probleem. Dat ging zelfs zo ver dat Hayek in 1981 zich in de Chileense krant El Mercurio uitsprak voor het regime van Pinochet, onder het motto ' $[. .$.$] personally, I prefer a liberal dictator to a democratic government$ lacking in liberalism' (Biebricher 2018a: 73). Daar ligt een reeks van theoretische bezwaren tegen democratie aan ten grondslag. Het gaat dan niet alleen om de bekende vrees voor de tirannie van de meerderheid en de invloed van goed georganiseerde minderheden (waarbij de tegenstelling tussen de irrationaliteit van de massa en de instrumentele rationaliteit van belangengroepen wijst op interne spanningen in de neoliberale theorievorming). In feite gaat iedere vorm van besluitvorming die de staat dwingt om in te grijpen in sociale verhoudingen tegen het neoliberale credo dat de markt beschermd moet worden. Dat leidt tot uiteenlopende voorstellen tot constitutionele inperking van democratische besluitvorming, met name in de vorm van vaststaande regels over de beperking van 
overheidsbestedingen. Maar het leidt bij Hayek ook tot voorstellen voor beperkingen aan politieke participatie en democratische vertegenwoordiging tot een eenmalige mogelijkheid tot kandidaatstelling voor 45 -jarigen, te verkiezen voor een parlement met een individuele zittingsduur van 15 jaar - het klinkt ondemocratisch, maar verschilt de facto niet heel veel van de huidige samenstelling van het parlement en de zittingsduur van volksvertegenwoordigers.

Deze beperking van de democratie dringt de neoliberale politieke theorie evenwel in een nieuw dilemma. Neoliberalen wantrouwen democratische besluitvorming vanwege het gebrek aan zelfbeheersing van volksvertegenwoordigers, maar als zij geen regels voor de begrenzing van staatsingrijpen kunnen stellen, wie moet dat dan wel doen? De veronderstelling dat ieder individu het beste zijn eigenbelang kan dienen impliceert de verwerping van een alwetende wetgever die voor het algemeen belang kan optreden - en dat geldt dus ook voor een neoliberaal verlichte despoot. Dat neemt niet weg dat zelfs een neoliberaal als Hayek, die zich keert tegen de rationalistische utopie van een wetenschappelijke planning van de economie, toch een rol ziet voor het 'helpful insight science can provide for the guidance of policy' (Biebricher 2018a: 132), zolang dat maar beperkt blijft tot een algemeen begrip van een marktordening, en zich niet vertilt aan specifiek economisch beleid.

Uiteindelijk leiden deze denkbeelden volgens Biebricher tot een impasse in neoliberale hervormingspolitiek. Hoewel auteurs als Röpke een beroep doen op 'aristocrats of the public spirit', die als wetenschappelijk gevormde elite voor kunnen gaan in een neoliberaal hervormingsbeleid, moeten neoliberalen toegeven dat er voor een dergelijke rol in politiek theoretisch opzicht eigenlijk geen ruimte is. De ironische conclusie van Biebrichers analyse van het neoliberale gedachtengoed is dat de neoliberale duivel niet alleen zijn bestaan verhult, maar volgens neoliberalen zelfs niet kan bestaan.

\section{Neoliberale hervormingspolitiek}

Deze theoretische conclusie compliceert de ambitie om een schets te geven van neoliberale beleidspraktijken. In de literatuur over het neoliberalisme ligt hier precies de grote uitdaging: hoe zijn de veelheid en variëteit aan denkbeelden die onder de vlag van het neoliberalisme verkondigd zijn van invloed op beleidspraktijken en uitkomsten van dat beleid - de zaken die het neoliberalisme tot etiket hebben gemaakt van alles wat er de afgelopen decennia fout is gegaan in het kapitalisme en de liberale democratie?

In Neoliberalismus zur Einführung (2012) benadrukt Biebricher dat deze beleidsmatige neoliberalisering geen exclusief Anglo-Amerikaans verschijnsel is, maar zich ook voordoet in Latijns-Amerika, Afrika, Azië, Oost-Europa en China. Aanjager van neoliberalisering was veelal een economische crisis, waarna het Internationaal Monetaire Fonds (IMF) en de Wereldbank intervenieerden, en in samenspraak met de Amerikaanse Federal Reserve Bank in de zogeheten 
'Washington Consensus' een samenhangend pakket van maatregelen oplegden: begrotingsdiscipline, monetarisme, vrijhandel, versterking eigendomsrechten, deregulering, privatisering. Tegelijk zijn er belangrijke nationale verschillen. Met een verwijzing naar het werk van Jamie Peck en Adam Tickel, concludeert Biebricher dat 'neoliberalism only exists in such hybrid "messy" forms' (Biebricher 2012: 97). Vervolgens schetst Biebricher in detail het Duitse hervormingsbeleid, waarbij de 'messiness' het lijkt te winnen van de ordelijkheid van het neoliberale paradigma, om ten slotte te concluderen dat het neoliberalisme de financiële crisis van 2008 in ordoliberale vorm heeft overleefd.

Die bevindingen werkt Biebricher verder uit in The Political Theory of Neoliberalism (2018a) maar ook in de bundel die hij uitbracht in 2017 samen met Frieder Vogelmann van het Socium Forschungszentrum Ungleichheit und Sozialpolitik van de universiteit van Bremen: The Birth of Austerity. German Ordoliberalism and Contemporary Neoliberalism. Die bundel is een intrigerend, maar ook nogal onsamenhangend samenraapsel van twee onderdelen. Het eerste deel bevat Engelse vertalingen van Duitstalige ordoliberale bijdragen: naast capita selecta uit het werk van Rüstow, Eucken en Franz Bohm, ook de vertaling van het Ordo Manifesto dat de laatste twee in 1936 samen met Hans GroßmannDoerth publiceerden. Die vertalingen zijn zonder meer nuttig voor het streven van Biebricher om het neoliberale denken te ontsluiten, maar geven geen uitsluitsel over hoe dat van invloed is geweest op de Europese politiek. Het tweede onderdeel bestaat uit een aantal bijdragen van hedendaagse Duitse (en een Finse) auteurs. Twee van die bijdragen betreffen de stelling die ook centraal staat in het tweede deel van The Political Theory of Neoliberalism, dat de Europese integratie sinds de Tweede Wereldoorlog getekend is door het ordoliberalisme, en dat met name na 2008 onder Duitse druk een ordoliberaal bezuinigingsbeleid is doorgevoerd.

In dat verband wijst Biebricher op een opvallende tegenstelling tussen de Verenigde Staten en Europa. In de VS leidde de financiële crisis tot een keynesiaans interventionisme, met zevenhonderd miljard dollar voor het Troubled Asset Relief Program, een programma voor infrastructurele investeringen (de American Recovery and Reinvestment Act), ondersteuning van de autoindustrie in het Cash for Clunkers-programma, verlaging van de rentevoet en quantitative easing door de Federal Reserve Bank. Daarentegen werd in Europa na een korte periode het keynesianisme weer verlaten, toen in oktober 2009 de Griekse staatsschuld veel hoger bleek uit te pakken dan voorspeld en Griekse obligaties werden afgewaardeerd naar de junkstatus van BBB-. De vrees voor fiscale besmetting van andere Europese landen leidde tot het 'one-size fits all' bezuinigingsbeleid - de 'politics of austerity' die Biebricher met de woorden van Mark Blyth defineert als 'a form of voluntary deflation in which the economy adjusts through the reduction of wages, prices, and public spending to restore competitiveness, which is (supposedly) best achieved by cutting the state's budget, debts, and deficits' (Blyth 2013: 2). Dit beleid werd koppig voortgezet, hoewel het resulteerde in economische krimp en de dubbele dip van de recessie van 2011 tot 2013. In vergelijking met de VS leidde dit beleid tot structureel 
lagere groeicijfers, hogere werkloosheid en een lagere levensverwachting. En als gevolg van hogere werkloosheidsuitkeringen en lagere belastinginkomsten kromp de staatsschuld niet, maar groeide die stevig door. De vraag is volgens Biebricher derhalve: 'If even the traditionally fiscally hawkish Americans advised against it, if the markets were ambiguous at best, and if it subjects entire populations to at times unbearably harsh sacrifices, why was the politics of austerity pursued in such a single-minded manner in Europe?' (Biebricher 2018a: 168).

De kern van Biebrichers antwoord op die vraag is dat dit het gevolg is van een ordoliberale ideologie, om niet te zeggen ideologische verblinding, die bovenal toegeschreven moet worden aan de Duitse hegemonie in de Europese politiek. Op het eerste gezicht weet Biebricher dit antwoord op overtuigende wijze te onderbouwen. Hij wijst op een reeks van maatregelen gericht op financiële disciplinering van de zwakke broeders in de Europese Unie: na de Europese Financiële Stabiliteitsfaciliteit (2010) volgde het Europees Stabiliteitsmechanisme (2011), vergelijkbaar met de Structural Adjustment Programs van het IMF. Samen met de Europese Commissie en de Europese Centrale Bank (ECB) vormde het IMF de Troika, die landen als Griekenland en Portugal een bezuinigingsregime oplegde, dat nog verder werd aangescherpt met de zogeheten Six-Pack, waarin naast het Stabiliteits- en Groeipact van 1996-1997 (met een maximaal begrotingstekort van drie procent en een staatsschuld van maximaal zestig procent van het BNP) werd aangevuld met een reeks aanvullende limieten en sancties. Daarop volgde de TwoPack, waarmee het begrotingsbeleid van nationale overheden werd gereguleerd. En ten slotte was er het Treaty on Stability, Coordination and Governance en de daaruit voortvloeiende Europese begrotingsunie, die veel van de genoemde maatregelen en sancties ook afdwingbaar maakten door het Hof van Justitie. Het zijn allemaal maatregelen in de trant van het schuldenplafond en begrotingsregels die met name de Amerikaanse neoliberaal James Buchanan aanwees als de kern van het neoliberale programma, gericht op het afschermen van de markt voor de invloeden van politieke besluitvorming.

\section{Een ordoliberaal Europa onder Duitse leiding?}

Minder overtuigend wordt Biebrichers betoog als hij niet alleen de overeenkomst tussen neoliberale ideeën en Europese praktijken wil demonstreren, maar ook wil aantonen dat het eerste de oorzaak van het tweede is. Die stelling probeert hij op drie, allemaal even onbevredigende manieren te onderbouwen. De eerste is een lange, maar weinig verhelderende theoretische exercitie, waarin hij wijst op de doorslaggevende invloed van ideeën op institutionele veranderingen. Hij maakt het zich daarbij extra moeilijk door de gedachten af te wijzen van Mark Blyth, Colin Hay, en bovenal de neoliberale theoreticus Frank Knight, dat die ideële invloed zich in het bijzonder laat gelden op momenten van onzekerheid, niet alleen over de juiste strategie om een doel te bereiken, maar nog fundamenteler over de doelen en 
belangen die men zou moeten nastreven. Volgens Biebricher zijn er mogelijk zulke crises, maar zijn dat slechts momentane verhevigingen van de structurele ideële aard van belangen, doelen en strategieën. Daaruit trekt hij de verrassende - en wellicht ook hoopvolle - conclusie, dat '[...] the status quo is never quite as locked in as neoliberal accounts suggest' (Biebricher 2018a: 200), maar veel wijzer over de vraag of Europees integratiebeleid door ordoliberale ideeën is ingegeven word je hier niet van.

Een tweede antwoord is dat het Europese integratiebeleid altijd al ordoliberaal van aard was, en dat het beleid na de financiële crisis van 2008 daarop voortborduurde. Biebricher wijst met name op de analyse van het Keulse Max Planckinstituut, met sociaal-wetenschappers zoals Fritz Scharpf, Wolfgang Streeck en Martin Höpner, die in een eerdere fase van hun carrière het ontstaan van een interne markt als voorwaarde zagen voor efficiëntere allocatie en grotere concurrentie tussen markpartijen. Het probleem van die gedachte is dat sommige neoliberalen zich nadrukkelijk van de Europese Unie hebben gedistantieerd. Zo vreesde Röpke de dialectiek waarin interne liberalisering kon leiden tot extern protectionisme, maar ook dat de Europese integratie zou leiden tot een keynesiaanse superstaat.

Een derde antwoord is dat het allemaal de schuld is van de Duitsers. Biebricher wijst op een 'considerable amount of circumstantial and anecdotal evidence' (Biebricher 2018a: 202) dat de Bondsrepubliek, en dan met name de ministeries van Economische Zaken en Financiën, en de Bundesbank, vanaf de jaren vijftig bolwerken van neoliberalisme waren. Voor de recentere periode wijst hij met name op de rol van Jürgen Stark, die bij alle drie de instellingen werkte voor hij in 2006 aantrad als directielid van de ECB, net als zijn opvolger Jörg Asmussen. Ook voorspelde Biebricher, zeer riskant voor een boek over zulke dynamische processen, dat Mario Draghi wel eens opgevolgd zou kunnen worden door Jens Weidman, die ook zo'n neoliberaal profiel zou hebben. Op dit punt lopen evenwel de eigenlijke politieke verhoudingen uit het neoliberale spoor. Niet alleen stond Weidman tegenover Asmussen in de vraag of de ECB op grote schaal obligaties moest opkopen, maar was dit ook het breekpunt dat Stark in 2011 al had genoopt bij de ECB op te stappen. En ten slotte werd Draghi niet opgevolgd door Weidman, maar door Christine Lagarde, die bij haar aantreden allerminst neoliberale geluiden liet horen.

Nog ingewikkelder wordt het verhaal in het licht van de bijdragen van Brigitte Young aan de bundel The Birth of Austerity (Biebricher en Vogelmann 2017). De vraag in de titel van haar bijdrage, 'Is Germany's and Europe's crisis politics ordoliberal and/or neoliberal?', beantwoordt zij ontkennend. Haar argument is dat in de Bundesbankgesetz van 1957 Euckens idee om monetaire politiek te binden aan een 'rationeel automatisme' verworpen werd ten gunste van het idee dat de bank in zijn beleid over discretionaire ruimte (en dus de mogelijkheid van een politieke afweging) diende te beschikken. Young betoogt dat het Europese monetaire beleid zich zonder problemen laat verklaren aan de hand van standaard neoklassieke economische theorie, maar bovenal ingegeven lijkt te zijn door onversneden Duits 
nationaal belang. Youngs betoog wordt in belangrijke mate gesteund door de bijdrage van Christian Joerges aan dezelfde bundel. Joerges concludeert dat het Verdrag van Maastricht van 1992 leidde tot een "market without a state", and its member states may become "states without markets"' (In Biebricher en Vogelmann 2017: 205). Het gebrek aan afdoende regulering van de Europese markt zou volgens hem op weinig ordoliberale waardering kunnen rekenen - een conclusie die haaks staat op Biebrichers visie dat Europa niet lijdt onder een gebrek maar aan een overdaad aan ordoliberalisme.

Deze controverse heeft Biebricher voortgezet in discussie met Josef Hien (postdoc in Florence en Stockholm) en Christian Joerges (emeritus hoogleraar Europees recht aan de Berlijnse Bertie Hochschule) in hun bundel Ordoliberalism, Law, and the Rule of Economics (Hien en Joerges 2017a), met daarin naast bijdragen van Biebricher en Young langs bovenstaande lijnen, een reeks bijdragen over ordoliberale invloed in Europa en verschillende Europese lidstaten. Ook daar is weer een bijdrage te vinden, nu van Angela Wigger (als universitair hoofddocent Internationale Betrekkingen verbonden aan de Radboud Universiteit) met de veelzeggende titel 'Debunking the Myth of the Ordo-Liberal Influence on PostWar European Integration'. Hien en Joerges besluiten hun inleiding tot de bundel dan ook met een uiterst voorzichtige conclusie: 'Despite all the above-mentioned doubts regarding the straightforwardness of the ordoliberalisation of Europe thesis, we still think it is worth exploring the connection between ordoliberalisrn, Germany and European integration' (2017a: 9) Net als Biebricher, wijzen zij erop dat in het bijzonder na de crisis van 2008, het failliet van het Anglo-Amerikaanse neoliberalisme althans in Duitsland, maar wellicht daarmee ook in Europa, heeft geleid tot een herwaardering van het ordoliberale gedachtengoed, maar dan met name in de vorm van een electoraal aansprekende (en overigens ook religieus gemotiveerde) cultuurkritiek, en veel minder in een uitgewerkt programma van politiek-economische ordening. In reactie op dezelfde stelling in het tijdschrift Leviathan (Hien en Joerges 2017b) formuleerde Biebricher een repliek (2018b). Daar wijst Biebricher opnieuw op het ordoliberale karakter van het Europese crisisbeleid nog steeds zonder eenduidig betoog hoe je uit gelijkenis tussen ideeën en praktijken ook de invloed van het ene op het andere kan aantonen.

\section{Een neoliberale gouvernementalité?}

Een laatste reddingsboei voor het idee dat de Europese politiek een ordoliberaal stramien volgt vormen de twee laatste bijdragen aan de bundel The Birth of Austerity (Biebricher en Vogelmann 2017). Daarin gaan de Finse filosoof Johanna Oksala en de Kasselse socioloog Lars Gertenbach in op Foucaults analyse van een neoliberale gouvernementalité. Het werk van Foucault vormt een eigenaardig onderdeel van de studie van het neoliberalisme: twee decennia voor de huidige generatie van neoliberalisme-onderzoekers, had Foucault in 1979 in zijn lezingen voor het Collège 
de France al een groot aantal van de thema's uit de vroege ordoliberale literatuur geanalyseerd, en ook gewezen op de verschillen met het latere neoliberale werk. Maar ook had hij een aan beide stromingen ten grondslag liggende denkfiguur ontwaard, in de vorm van een neoliberale subjectvorming - de vorming van de ondernemende mens, het human resource management, de ethiek van de markt - die als essentieel onderdeel van een neoliberale biopolitiek gezien moest worden (de term had Foucault al eerder gemunt, maar de parallellie met Rüstows concept Vitalpolitik is opvallend).

In Biebrichers Neoliberalismus zur Einführung (2012) vormde Foucaults biopolitieke perspectief een derde luik van zijn analyse, dat naast de ideeën en 'messy' beleidspraktijken een losstaand onderdeel van het boek bleef. In The Political Theory of Neoliberalism (Biebricher 2018a) is Foucault geheel afwezig, en ook in The Birth of Austerity (Biebricher en Vogelmann 2017) speelt zijn visie een bescheiden rol. Maar in het licht van de moeite die het kost om de neo- of ordoliberale invloed te peilen, is Foucaults analyse misschien wel doorslaggevend. Zoals Oksala in haar bijdrage 'Ordoliberalism as governmentality' betoogt (maar weinig onderbouwt), is het ordoliberalisme 'a coherent political rationality, a consistent theoretical framework underlying EU governance, even if it is at times unevenly articulated and implemented' (in Biebricher en Vogelmann 2017: 198). Dit sluit aan bij de evenmin diepgravend uitgewerkte gedachte in de inleiding van Biebricher en Vogelmann bij The Birth of Austerity dat er een ordoliberaal wereldbeeld aan de Europese politiek ten grondslag ligt. Op zich is het inderdaad opvallend met hoeveel moralisme het beleid van de Troika gepaard ging. In dat licht van de uitspraak van Jeroen Dijsselbloem, dat het Griekse probleem was dat ze hun geld verbrasten aan drank en vrouwen geen slip of the tongue. Zoals Biebricher en Vogelmann stellen:

The emphasis on personal responsibility, the moral condemnation of debts (often in the name 'of our children') or the rigorism with which it defends the absolute necessity of 'playing by the rules' and 'doing one's homework' - all these moral notions partly disguised as economic doctrines are if not taken straight out of ordoliberalism's rhetoric then at least well prepared by it. (2017: 8-9)

Een dergelijke observatie is inderdaad intrigerend, maar het is na een zeer diepgravende analyse van het neo- en ordoliberale ideeëngoed, en een zeer geïnformeerde en gedetailleerde uiteenzetting van de Duitse en de Europese politiek wel een erg dun lijntje dat ideeën en praktijken met elkaar verbindt. Zonder een grondiger analyse van de intellectuele en politieke achtergrond van de hoofdrolspelers in het Europese beleid, van de debatten die in Brussel en Straatsburg, maar ook in de ministeries en in de ministerraden gevoerd worden, en van de ethische, ontologische en handelingstheoretische vooronderstellingen die aan Europees beleid ten grondslag liggen, verdwijnt het neoliberalisme in Biebrichers werk steeds verder achter de horizon. 


\section{Literatuur}

Biebricher, Thomas (2005) Selbstkritik der Moderne. Habermas und Foucault im Vergleich. Frankfurt am Main: Campus Verlag.

Biebricher, Thomas (2012) Neoliberalismus zur Einführung. Hamburg: Junius Verlag.

Biebricher, Thomas (2017) Onvermoed en onvermijdelijk. De vele gezichten van het neoliberalisme. Nijmegen: Valkhof Pers.

Biebricher, Thomas (2018a) The Political Theory of Neoliberalism. Stanford: Stanford University Press.

Biebricher, Thomas (2018b) Zur Ordoliberalisierung Europas - Replik auf Hien und Joerges. Leviathan, 46(2): 170-188

Biebricher, Thomas en Frieder Vogelmann (red.) (2017) The Birth of Austerity. German Ordoliberalism and Contemporary Neoliberalism. Londen: Rowman \& Littlefield. Friedman, Milton (2002) Capitalism and Freedom. Chicago: University of Chicago Press. Hien, Josef en Christian Joerges (red.) (2017a) Ordoliberalism, Law, and the Rule of Economics. Oxford: Hart.

Hien, Josef en Christian Joerges (2017b) Das aktuelle Interesse an der ordoliberalen Tradition. Leviathan, 45(4): 459-493.

\section{Ido de Haan}

Ido de Haan is hoogleraar politieke geschiedenis aan de Universiteit Utrecht. Hij is projectleider van het NWO-onderzoeksproject Market Makers, over de geschiedenis van neoliberalisme in Nederland. Zijn onderzoek richt zich in bredere zin op de geschiedenis van het politieke denken, de ontwikkeling van burgerschap, staat en burgerlijke maatschappij in WestEuropa en de Nederlandse politieke geschiedenis in de negentiende en twintigste eeuw. 